\title{
A PRODUÇÃO DA FAMÍLIA NO BRASIL CONTEMPORÂNEO: UMA ANÁLISE DE LEIS E DECISÕES JURÍDICAS
}

\author{
LA PRODUCCIÓN DE LA FAMILIA EN EL BRASIL CONTEMPORÁNEO: UN \\ ANÁLISIS DE LEYES Y DECISIONES JURÍDICAS
}

\author{
THE FORMATION OF THE FAMILY IN CONTEMPORARY BRAZIL: AN ANALYSIS \\ OF LAWS AND LEGAL DECISIONS
}

\author{
Luciana KORNATZKI ${ }^{1}$ \\ Paula Regina Costa RIBEIRO ${ }^{2}$
}

RESUMO: A família pode ser concebida como um dispositivo que articula determinados discursos que são postos em disputa em torno da sua definição. Assim, seu entendimento está relacionado aos discursos que sobre ela são produzidos. Valemo-nos de enunciações produzidas por algumas leis e decisões jurídicas que possibilitam a ampliação do conceito de família e o reconhecimento da conjugalidade homossexual, fatos que provocaram grupos religiosos e políticos em defesa da família nuclear. Temos como objetivo examinar algumas formas de atuação do sistema jurídico para a produção do entendimento de família na atualidade. Para isso, apresentamos uma abordagem histórica sobre a família moderna, a partir de um olhar foucaultiano e estabelecemos uma relação com a noção de dispositivo. Em seguida, analisamos algumas leis e decisões jurídicas que versam sobre uma forma ampla de conceber a família, em suas diferentes possibilidades de arranjos. Compreendemos que essa ampliação do conceito provoca a atualização do dispositivo da família. Essa atualização se dá na medida em que produz novas formas de vivenciar a família, através de outras relações de saber-podersubjetividade que interpelam os sujeitos.

PALAVRAS-CHAVE: Família. Sistema jurídico. Dispositivo. Discursos.

RESUMEN: La familia puede ser concebida como un dispositivo que articula determinados discursos puestos en conflicto a causa de su definición. Así, la comprensión que se tiene de esta está relacionada con los discursos producidos en torno a ella. Nos valemos de enunciados producidos por algunas leyes y decisiones jurídicas que posibilitan la ampliación del concepto de familia y el reconocimiento de la conyugalidad homosexual, hechos que han movido a grupos religiosos y políticos en defensa de la familia nuclear. Tenemos como objetivo examinar algunas formas de actuación del sistema jurídico en la producción de la comprensión de la familia en la actualidad. Para ello, hacemos un abordaje histórico sobre la familia moderna, a partir de una mirada foucaultiana y establecemos una relación con la noción de dispositivo. Acto seguido, analizamos algunas leyes y decisiones jurídicas que versan sobre una forma amplia de concebir la familia en sus diversas configuraciones posibles. Comprendemos que

\footnotetext{
${ }^{1}$ Universidade Federal do Rio Grande (FURG), Rio Grande - RS - Brasil. Doutoranda no Programa de PósGraduação em Educação em Ciências: química da vida e da saúde (associação ampla FURG-UFRGS-UFSM). ORCID: <http://orcid.org/0000-0002-2677-2354>. E-mail: lukornatzki@ gmail.com

${ }^{2}$ Universidade Federal do Rio Grande (FURG), Rio Grande - RS - Brasil. Professora Titular - Instituto de Educação. ORCID: <http://orcid.org/0000-0001-7798-996X>. E-mail: pribeiro.furg@ gmail.com
} 
esa ampliación del concepto provoca la actualización del dispositivo de la familia. Dicha actualización se da en la medida en que produce nuevas formas de vivenciar la familia, a través de otras relaciones de saber-poder-subjetividad que interpelan a los sujetos.

PALAVRAS CLAVE: Familia. Sistema jurídico. Dispositivo. Discursos.

ABSTRACT: Family can be conceived as a dispositive that articulates certain discourses that are put in contest around its definition. Thus, its understanding is related to the discourses that are produced about it. We use statements produced by some laws and legal decisions that allow the expansion of the concept of family and the recognition of homosexual conjugality, facts that provoked religious and political groups in defense of the nuclear family. We aim to examine some forms of legal system performance for the production of family understanding in present. For this, we present a historical approach on the modern family, from a Foucaultian look and establish a relation with the notions of dispositive and governmentality. Next, we analyze some laws and legal decisions that deal with a broad way of conceiving the family, in their different possibilities of arrangements. We understand that this extension of the concept causes the family governance dispositive to be updated. This updating occurs insofar as it produces new ways of experiencing the family, through other relations of know-power-subjectivity that interpellate the subjects.

KEYWORDS: Family. Legal system. Dispositive. Discourses.

\section{Introdução}

O debate sobre o significado de família, frente ao reconhecimento das diversas configurações familiares, tem suscitado várias discussões em diferentes âmbitos da sociedade brasileira. O campo jurídico e legislativo, bem como ações da sociedade civil e religiosa, tem mobilizado debates adversos, constituindo uma luta composta por dois lados antagônicos. De um lado, grupos a favor da ampliação do conceito de família, de outro, grupos contra esse movimento.

Assim, a produção da família no Brasil contemporâneo assume uma complexificação resultante de vários fatores, sendo um deles o alargamento jurídico e político do conceito, o que provoca uma amplitude de possibilidades de reconhecimento de diferentes arranjos familiares.

As relações entre sistema jurídico e família precisam, portanto, ser analisadas a partir do modo como o poder desse se exerce na produção de subjetividades. Duas das formas de ação do poder do sistema jurídico sobre a família são a produção de leis e as decisões jurídicas que versam sobre essa instância.

Ao abordarmos o poder, não é no sentido de que ele atua na repressão ou de que alguns grupos ou indivíduos o detém sobre outros. Entendemos que o poder produz e circula entre as 
pessoas. De acordo com Michel Foucault (2015b, p. 284) "o poder funciona e se exerce em rede. Nas suas malhas, os indivíduos não só circulam, mas estão sempre em posição de exercer esse poder e de sofrer sua ação". Assim, ainda que trabalhemos com o sistema jurídico, partimos de uma “[...] uma concepção não jurídica de poder, segundo o qual é impossível entendê-lo se ele for definido como um fenômeno que diz fundamentalmente respeito à lei ou à repressão" (MACHADO, 2015, p. 18).

Compreendendo-se que o poder produz e circula, entendemos que o sistema jurídico, por meio de leis e decisões jurídicas sobre a família, viabiliza acontecimentos que são produtos de relações de força, os quais colocam em disputa determinados significados em torno de sua definição.

Neste trabalho, o interesse se dá sobre o entendimento de família evidenciado por algumas leis e decisões jurídicas que versam sobre a ampliação do conceito de família e sobre o reconhecimento da conjugalidade homossexual, fatos que provocaram grupos religiosos e políticos em defesa da família nuclear.

Nesse sentido, temos por objetivo examinar algumas formas de atuação do sistema jurídico para a produção do entendimento de família na atualidade brasileira. Para tanto, apresentamos inicialmente alguns elementos históricos sobre a produção da família moderna e estabelecemos relações com o conceito foucaultiano de dispositivo (FOUCAULT, 2015a; FOUCAULT, 2015b; FOUCAULT, 2008).

$\mathrm{Na}$ sequência, produzimos uma análise dessas leis e decisões jurídicas, na qual visibilizamos a atualização do que temos entendido por dispositivo da família, a partir da compreensão da existência de diferentes configurações familiares. Contudo, essa atualização não se exerce linearmente, já que sofre embates e lutas contrárias provenientes de grupos que alegam ser a família nuclear heterossexual o modelo legítimo. Tais embates também são próprios da atualização do dispositivo, já que ele se constitui por relações de poder e onde há poder, há resistências. Assim, procuramos tecer algumas considerações sobre o Projeto de Lei 6.583/2013, conhecido como Estatuto da Família, que combate o alargamento do conceito. Entendemos que a produção da família como dispositivo, articulada ao sistema jurídico, resulta em processos de controle e governo da população, de produção de diferentes subjetividades e envolve a conquista ou negação de direitos, assim como o combate ou apoio à diferença e, em última instância, o fortalecimento ou combate ao preconceito e à LGBTfobia. 


\section{Um olhar foucaultiano sobre a família}

Realizamos uma abordagem histórica da família e para isso buscamos nos inspirar no modo foucaultiano de fazer história, de tal modo que não procuramos por uma origem, no sentido metafísico. A genealogia procura acontecimentos e suas dispersões, preocupa-se com as condições de proveniência e emergência (FOUCAULT, 2015b). Assim, ao olharmos para alguns elementos da história da família, a partir de Michel Foucault e tomando como marco a família moderna, pretendemos observar as condições de possibilidade de sua emergência.

Foucault (2001, 2006), ao abordar a produção da família moderna, nos possibilita identificar algumas condições de possibilidade para sua construção enquanto uma família sexualizada. Por meio da ciência psiquiátrica, produziu-se uma articulação que relacionou a produção da família ao dispositivo da sexualidade.

Por volta do século XVIII, segundo Foucault (2001), desenvolveu-se uma nova organização do espaço familiar que buscou a eliminação dos/as intermediários/as na relação pais-filhos, transformando o espaço da família em vigilância contínua. Conforme o autor, desenvolve-se uma cruzada antimasturbação, isto é,

na hora do banho, de deitar, de acordar, durante o sono, as crianças devem ser vigiadas. Em torno das crianças, em suas roupas, em seu corpo, os pais devem estar à espreita. $\mathrm{O}$ corpo da criança deve ser objeto de sua atenção permanente (FOUCAULT, 2001, p. 311).

Há, assim, por meio da perseguição e proibição da sexualidade da criança, a constituição de um novo corpo familiar, é a família-célula, família restrita, família corporal e substancial (FOUCAULT, 2001). Foi valorizando o corpo da criança, a sua sexualidade, a sua atividade masturbatória, que se possibilitou a redução do espaço doméstico, constituindo pais e filhos/as um corpo único, de vigilância constante sobre o autoerotismo infantil, ao mesmo tempo em que se estreitou as relações entre eles/as. Para Foucault (2001, p. 315), "trata-se de constituir uma família-canguru: o corpo da criança como elemento nuclear do corpo da família".

Foucault (2001) destaca que foi a problematização da relação corpo-a-corpo entre pais e filhos/as que pôde intensificar o tema do incesto, bem como tornar aceitável a teoria psicanalítica nessa questão. Mas, para isso, colocou-se o desejo incestuoso na criança para com os pais e tornou-se o incesto a origem das pequenas anomalias, o que reforçou a ideia da necessidade de intervenção do saber médico na família. Desse modo, a teoria psicanalítica do incesto, inscrevendo-se no interior da cruzada antimasturbação, produziu uma normalização médica da família. Contudo, segundo Foucault (2001), essa campanha que visava a aproximação entre pais e filhos esteve direcionada à família burguesa. 
A família popular, a família do proletariado urbano que se constituía, foi produzida outra campanha que teve por foco o casamento e sua solidificação. Essa campanha de solidificação matrimonial do proletariado juntou-se ainda a outra, voltada à especificação das relações familiares e diferenciação entre indivíduos, idades e sexos. É assim que se deu outra relação entre pais e filhos/as nas famílias proletárias. Escreve Foucault (2001, p. 344): "nada de corpoa-corpo, nada de contatos, nada de misturas". O incesto muda de problemática, o perigo não reside mais nas crianças, mas se volta à relação irmão-irmã e pai-filha. Nesse caso, não se deve aproximar, mas sim afastar-se.

Assim, nas famílias burguesas, a vigilância sobre o corpo da criança incentivou os pais a dormir com seus filhos e filhas, se possível na mesma cama. Nas famílias do proletariado, a partir da produção do perigo do incesto entre pai-filha ou irmã-irmã, a campanha foi no sentido de que o casal e seus filhos e filhas dormissem em quartos separados (FOUCAULT, 2001).

Percebe-se, então, dois medos em relação ao incesto, de um lado a família burguesa e, de outro, a família operária. Contudo, destaca Foucault (2001) que em determinado momento elas sofrem um intercâmbio, formando um modelo familiar 'interclasses'. 'É a pequena célula pais-filhos, cujos elementos são diferenciados, mas poderosamente solidários, e que são ao mesmo tempo ligados e ameaçados pelo incesto" (FOUCAULT, 2001, p. 345). O elemento incesto é o que, de certo modo, as unifica.

Porém, esse intercâmbio não significa que se apagam as diferenças, pois de um lado a sexualidade da criança requer a união da família, de outro a sexualidade do adulto pede a sua repartição. Sobre elas passa a haver dois modos autoritários de intervenção. No caso da burguesia, tem-se a medicina psicanalítica no controle da sexualidade infantil e, no caso do proletariado, tem-se o poder judiciário e as instituições de policiamento das famílias populares. Tanto em um caso quanto no outro, a psiquiatria atua, pois mesmo que aparentemente ela não esteja presente no controle da família proletária, ela está lá inserida ao exercer influência também na produção do poder judiciário (FOUCAULT, 2001).

Foucault (2006), ao acentuar o modo como a psiquiatria se apropriou do discurso da família para produzir saber e exercer poder, relaciona também a emergência da família celular ao surgimento dos dispositivos disciplinares ${ }^{3}$, tal como a psiquiatria o é. Para ele, a família exerce uma função determinante e indispensável na constituição dos dispositivos disciplinares,

${ }^{3}$ Um dispositivo disciplinar, segundo Foucault (2014) pode ser entendido como uma rede que articula instituições, leis, normas, enunciados de diferentes campos de saber, entre outros elementos, em torno do disciplinamento dos corpos, do seu esquadrinhamento para se subtrair o máximo de sua capacidade, para torná-los obedientes, bem como para regular, docilizar e enquadrar os corpos segundo determinadas normas que se supõe úteis. $\mathrm{O}$ autor cita como dispositivos disciplinares a fábrica, o quartel, a prisão, a escola, entre outros. 
pois é ela que vincula os sujeitos a esses dispositivos, bem como articula e faz circular os sujeitos entre um dispositivo e outro. Conforme suas palavras,

Quero dizer que a família é a instância de coerção que vai fixar permanentemente os indivíduos aos aparelhos disciplinares, que vai de certo modo injetá-los nos aparelhos disciplinares. É porque a família existe, é porque vocês têm esse sistema de soberania que age na sociedade sob a forma da família (FOUCAULT, 2006, p. 100).

Para Foucault (2006), a família é essencial ao poder disciplinar, embora ela não exerça esse tipo de poder. O poder que ela exerce é de tipo soberano, ou seja, a família é uma célula de soberania. Na família “[...] o pai, enquanto portador do nome e na medida em que exerce o poder sob seu nome, é o polo mais intenso da individualização, muito mais intenso do que a mulher e os filhos" (FOUCAULT, 2006, p. 99). Esse tipo de relação, segundo o autor, é característico do poder soberano e inverso ao poder disciplinar.

Acerca da constituição histórica da família moderna, Foucault (2006) ressalta que na sociedade disciplinar ${ }^{4}$ a família se concentrou, se intensificou e se limitou. Sobre este processo a lei teve um papel determinante. $\mathrm{O}$ autor traz como exemplo o código civil francês, também conhecido como Código Napoleônico, para afirmar que, pela ação da lei, "a família conservou os esquemas de soberania: dominação, pertencimento, vínculos de suserania, etc., mas ela os limitou às relações homem-mulher e às relações pais-filhos” (FOUCAULT, 2006, p. 103). O código civil fez com que a família fosse definida pelo núcleo pai-mãe-fillhos e, assim, “[...] constituiu um alvéolo de soberania pela ação do qual as singularidades individuais são fixadas aos dispositivos disciplinares" (FOUCAULT, 2006, p. 103).

Vemos assim o papel da lei na legitimação da família celular em torno de determinadas regras e padrões sociais específicos a cada sujeito, de acordo com as condições de possibilidade dadas em tal momento histórico. E essa força atribuída à família celular, segundo Foucault (2006), foi necessária para que os sistemas disciplinares pudessem se sobrepor aos sistemas de soberania, mas eles não os fizeram desaparecer. Podemos entender então que a família fortaleceu os dispositivos disciplinares e, ao mesmo tempo, foi fortalecida por eles.

\footnotetext{
${ }^{4}$ A sociedade disciplinar é definida por Foucault (2014) como um conjunto de estratégias que emergem por volta dos séculos XVII e XVIII que tem por objetivo o controle minucioso do corpo, para lhe extrair o máximo de sua capacidade. É nessa sociedade que nasce a prisão, a escola, o hospital, a fábrica, com estratégias próprias de disciplinamento dos corpos. Para o autor "o momento histórico das disciplinas é o momento em que nasce uma arte do corpo humano, que visa não unicamente o aumento de suas habilidades, nem tampouco aprofundar sua sujeição, mas a formação de uma relação que no mesmo mecanismo o torna tanto mais obediente quanto é mais útil, e inversamente" (FOUCAULT, 2014, p. 135).
} 
Conforme Foucault (2015b), um dispositivo se caracteriza por ser um tipo de formação que tem por finalidade responder a uma urgência histórica. Nessa direção, a emergência da família celular, articulada a instituições, normas e leis, surge para responder a uma urgência histórica que está ligada intrinsecamente ao desenvolvimento dos dispositivos disciplinares, dentre eles a medicina psicanalítica. Além disso, sua urgência também se liga à fixação do matrimônio e aos novos sentidos atribuídos às crianças, ao seu corpo e a sua sexualidade, bem como a própria constituição do dispositivo da sexualidade.

Foucault, (2015b) estabelece que um dispositivo corresponde a uma rede que articula distintos elementos, tais como instituições, leis, organizações arquitetônicas, discursos, enunciados científicos, proposições filosóficas, entre outros. Nesse sentido, diante de nossa incursão histórica, a partir de um olhar foucaultiano, podemos entender a família operando como dispositivo, ao se produzir de forma articulada a instituições médicas, jurídicas e de policiamento $^{5}$, assim como envolver leis, normas e regras atribuídas a cada sujeito na família, por exemplo a vigilância dos pais sobre o corpo da criança, o maior cuidado da mãe em relação aos/às filhos/as. Nesta rede também se valorizou o matrimônio, assim como foram produzidos discursos acerca do incesto e da sexualidade, provocando uma determinada organização arquitetônica dos espaços domésticos a partir do próprio medo do incesto.

Podemos observar, assim, a articulação do dispositivo da família a outros dispositivos, como o dispositivo da sexualidade, da aliança, bem como o dispositivo disciplinar, em que eles se reforçam e se produzem mutuamente em torno da construção de diferentes subjetividades.

Para Luis Garcia Fanlo (2011) os dispositivos capturam os indivíduos a partir de práticas discursivas e não discursivas que produzem formas de subjetividade. Ao capturá-los, os dispositivos produzem os sujeitos assujeitando-os a determinados efeitos de saber e poder. Assim, eles inscrevem nos corpos dos sujeitos modos e formas de ser muito específicos, cuja finalidade é governar, administrar e controlar os seus gestos, pensamentos e comportamentos de acordo com um sentido que se supõe útil. O dispositivo da família, possibilitou, então, a construção histórica e cultural das funções e papéis sociais específicos, atribuídos ao pai, à mãe e aos filhos e filhas. Por exemplo, prover e ser provido, cuidar e ser cuidado.

Garcia Fanlo (2011) nos ajuda a compreender que o dispositivo, como rede de relações que articula formas de exercício de poder e configurações de saber, torna possível determinados efeitos de verdade e realidade. Este autor nos auxilia também a entender a família como um dispositivo, ao afirmar que

${ }^{5}$ É importante também lembrar das relações que a família estabelece com outras instituições, como a escola, com outras instituições políticas, jurídicas, religiosas, as quais se articulam à produção dos sujeitos. 
un dispositivo es un régimen social productor de subjetividad, es decir, productor de sujetos-sujetados a un orden del discurso cuya estructura sostiene un régimen de verdad. De ahí que la familia, la fábrica, el hospital, la escuela, el cuartel, la iglesia, el club de fútbol, el partido político, la universidad, son dispositivos [...] (GARCIA FANLO, 2011, p. 7).

Nesse sentido, são inúmeros os dispositivos presentes na sociedade, pois dizem respeito àquelas instâncias sociais que produzem formas de subjetividade. O dispositivo da família, assim entendido, produz sujeitos que são submetidos a regimes de verdade, apoiados em uma determinada ordem do discurso. Que regime(s) de verdade pode $(m)$ ser este(s) que sustentam o dispositivo da família? Podemos pensar no sistema jurídico como um de seus exemplos, por ser pela lei, enquanto elemento do dispositivo, que se reconhece ou se exclui um significado ou uma forma de família. Pela sua força, a lei controla, delega, determina, pune, visibiliza e invisibiliza, enfim, produz subjetividades.

Podemos observar algumas formas da atuação do sistema jurídico sobre a produção e regulação da família, e assim de subjetividades, no modo como esse conceito tem sido ampliado nos últimos anos. A legalização do divórcio, o reconhecimento de diferentes configurações familiares, a possibilidade da união civil entre pessoas do mesmo sexo, são alguns exemplos de como a família, ou o que se entende por ela, tem sido alterado.

É preciso considerar, no entanto, outra contribuição foucaultiana nesta análise sobre o alargamento do conceito de família, bem como a esses processos de transformação no tratamento jurídico dado a essa instância. Foucault (2008) nos possibilita a pensar no modo como o Estado, por meio de determinadas estratégias, desenvolve uma arte de governo que tem por objetivo o controle, a governança e exercício do poder sobre a população, por meio de dispositivos de segurança. No entanto, para controlar a população, é pela família que se irá passar esse controle, por meio da estatística, de táticas de governo, de análises e procedimentos aplicados a essa instância. A família, nesse sentido, pode ser vista como um elemento de governamentalidade do Estado, ou seja, como elemento através do qual se desenvolveu e se desenvolve essa arte de governo voltada a nos governar e nos governarmos (FOUCAULT, 2008).

É nesse sentido que podemos compreender o ordenamento jurídico acerca da família como operação que visa a aplicação dessa arte de governo, a fim de governar a população através do governo das famílias, bem como de fazer com que os próprios sujeitos, nas famílias, se governem segundo as normas estabelecidas. Por exemplo, constituam ou dissolvam o casamento, se reproduzam e façam o registro filial, constituam e exerçam parentalidade segundo os deveres que cabem aos pais e/ou mães, controlem bens e patrimônio, etc. 
A família, compreendida como dispositivo, articula-se a outras instâncias e dispositivos, seus ditos e não ditos, leis, normas, saberes, preceitos, na produção dos sujeitos e subjetividades. Esse dispositivo, portanto, por meio das disposições jurídicas que atuam contemporaneamente, faz com que sejamos governados e nos governamos conforme determinadas normas, sentidos e significados.

\section{Ações jurídicas e legislativas para a família: a atualização do dispositivo}

O dispositivo da família articula, em sua produção, determinados discursos que são postos em disputa em torno da sua definição. Ao entendermos que os discursos formam os objetos dos quais falam, a família é, antes, produto dessa ordem do discurso, relacionado a relações de poder, saber e produção de subjetividades que a constituem. Para entendermos a família, é preciso olhar para os discursos que sobre ela são produzidos.

Na produção da família encontramos, por exemplo, os discursos do Direito e nele os enunciados jurídicos e legislativos. Enunciados são compreendidos não como atos de fala, frases ou proposições (FOUCAULT, 2004), mas como uma função que atravessa essas unidades, como algo que se articula aos discursos, de modo que discurso e enunciado se formam e se constituem mutuamente. Assim, enunciados jurídicos e legislativos constituem o discurso do Direito e são constituídos por ele, ao mesmo tempo em que contribuem na formação do discurso da família.

Os enunciados, conforme aponta Rosa Maria Bueno Fischer (2013, p. 142), são compostos por alguns elementos, sendo um deles a sua condição de materialidade, ou seja, “[...] as formas muito concretas com que ele aparece". Essa materialidade pode ser encontrada nas ações jurídicas e legislativas de um determinado tempo e lugar, através das enunciações produzidas, isto é, nas próprias frases, textos e decisões jurídicas e legislativas, as quais formam regimes de enunciação. Tomamos por ações legislativas a produção mesma de leis e por ações jurídicas as decisões tomadas em âmbito jurídico, por exemplo, pelo Supremo Tribunal Federal (STF).

Pelos discursos produzidos por meio de ações legislativas e jurídicas, são reconhecidas ou invisibilizadas formas de família, lhes garantindo ou não acesso aos direitos constitucionais. A Constituição Federal de 1988 (CF/1988) representou um avanço para a histórica negação da possibilidade de ampliação do significado de família. A Constituição ampliou sua proteção para as famílias constituídas para além do casamento, abarcando a união estável e a família 
monoparental. Além disso, reconheceu o direito igualitário dos/as filhos/as havidos fora do casamento ou por adoção. O reconhecimento das diversas formas de família torna-se, assim, importante, pois está relacionado ao exercício da cidadania, ao direito de liberdade e de dignidade (RIOS, 2011).

É preciso, entretanto, problematizarmos essa abertura constitucional para o reconhecimento de outros arranjos familiares para além do modelo nuclear. Lembramos Foucault (2015a), ao afirmar que

[...] as Constituições escritas no mundo inteiro a partir da Revolução Francesa, os códigos regidos e reformados, toda uma atividade legislativa permanente e ruidosa não devem iludir-nos: são formas que tornam aceitável um poder essencialmente normalizador (FOUCAULT, 2015a, p. 156).

Na sociedade disciplinar, o sistema jurídico opera no disciplinamento dos corpos, tendo como objetivo a sua normalização. Nesse sentido, a CF/1988, ao viabilizar tal entendimento de família, representa uma estratégia que tem por objetivo a normalização dessa instância e, com isso, adequar às normas sujeitos que estavam às suas margens. Ao afirmar que determinadas formas de organização entre as pessoas passam a ser reconhecidas como família, enquadra-as dentro de normas que não são aleatórias, mas produto de relações de saber e poder.

Respaldadas pela nossa Carta Magna, trazemos aqui duas leis que trazem a ampliação do conceito de família. Essa ampliação só se tornou possível, nos termos da Lei, pois a CF/1988, representou a emergência "[...] de um novo direito constitucional de família, que, muito além de romper com a ideia de família institucional, insere-se no paradigma dos direitos humanos e por meio dele deve ser interpretado e desenvolvido" (RIOS, 2011, p. 84).

Nessa direção, conforme aponta Roger Raupp Rios (2011, p. 84), a atualização do direito de família viabilizou "[...] o reconhecimento dos novos valores e das novas formas de convívio constituintes das concretas formações familiares contemporâneas", o que possibilitou expressar um entendimento amplo acerca do conceito de família nestas leis que exemplificamos a seguir. A primeira é a Lei 10.836/2004 que criou o Programa Bolsa Família. Em seu artigo $2^{\circ}, \S 1$, I, define família como

a unidade nuclear, eventualmente ampliada por outros indivíduos que com ela possuam laços de parentesco ou de afinidade, que forme um grupo doméstico, vivendo sob o mesmo teto e que se mantém pela contribuição de seus membros $(\mathrm{s} / \mathrm{p})$. 
A segunda, conhecida como Lei Maria da Penha, Lei n. 11.340/2006, compreende família como "a comunidade formada por indivíduos que são ou se consideram aparentados, unidos por laços naturais, por afinidade ou por vontade expressa" (s/p).

Desse modo, apoiadas em nossa Lei Maior, essas duas leis possibilitam que a família seja entendida e visibilizada para além do modelo nuclear, composto por pai, mãe e filhos/as, mas passe a comportar, como elementos que a definem, laços de afeto e/ou parentesco, que vivam em um mesmo lar ou a constituam a partir do próprio desejo de formá-la.

Assim, essas leis desvinculam a noção de família relacionada exclusivamente ao casamento, da necessidade de laços biológicos e da função da reprodução, ressaltando, entretanto, o compromisso entre seus membros.

A valorização de determinados aspectos na definição de família se torna possível pois está engendrada a saberes que tornam possível verdades, produto de práticas sociais. Segundo Foucault (2002, p. 8)

[...] as práticas sociais podem chegar a engendrar domínios de saber que não somente fazem aparecer novos objetos, novos conceitos, novas técnicas, mas também fazem nascer formas totalmente novas de sujeitos e sujeitos de conhecimento.

Desse modo, tal definição de família produz subjetividades, mas, ao mesmo tempo, só foi possível por derivar de saberes articulados a práticas sociais, práticas que tornaram possível a problematização da noção nuclear heterossexual de família como única possível. Nessas práticas sociais encontramos relações de poder, pois “[...] por trás de todo saber, de todo conhecimento, o que está em jogo é uma luta de poder. O poder político não está ausente do saber, ele é tramado com o saber" (FOUCAULT, 2002, p. 51). Nessa direção, Machado (2015, p. 28) nos ajuda a compreender que

Todo saber é político. E isso não porque cai nas malhas do Estado, é apropriado por ele, que dele se serve como instrumento de dominação, descaracterizando seu núcleo essencial, mas porque todo saber tem sua gênese em relações de poder.

Para produzir então um saber que entende de tal ou qual forma o significado de família, há toda uma articulação com relações de poder, o que possibilitou romper com a restrição do conceito aos laços de conjugalidade e consanguinidade, fazendo prevalecer os laços afetivos e o espaço doméstico como aspectos que a definem. Assim, essa noção ampliada de família tornase um marco ao possibilitar abarcar outros arranjos para além do modelo pai-mãe-filhos/as. 
A partir da existência de outros arranjos familiares, tais sujeitos passaram a reivindicar por direitos, exercendo poder, de tal forma que o sistema jurídico, de acordo com determinadas condições históricas, possibilitou a não restrição a um modelo único. Esse processo também favorece que outros sujeitos, por exemplo casais homossexuais, possam constituir união civil, realizar adoção ou exercer outros direitos sociais.

Para Foucault (2014, p. 10), o discurso produz poder, “[...] o discurso não é simplesmente aquilo que traduz as lutas ou os sistemas de dominação, mas aquilo porque, pelo que se luta, o poder do qual queremos nos apoderar”. A produção discursiva sobre família, assim, está envolvida em disputas adversas e não constitui um consenso comum, de tal modo que em termos legais ainda encontramos uma ênfase à noção de família relacionada à união entre homem e mulher.

Nesse sentido, evidenciamos o Código Civil brasileiro, como outra lei que regulamenta a família e assim contribui na produção discursiva sobre tal instância. Em sua última edição, do ano de 2002, registra-se a noção de entidade familiar como união estável entre homem e mulher. Em contraposição a essa referência do Código Civil ao sexo do/a cônjuge, tramitava no Senado o Projeto de Lei 612/2011 que buscava a exclusão dessa referência, reconhecendo família como união entre duas pessoas, permitindo a possibilidade, no Código Civil, do casamento entre pessoas do mesmo sexo. Entretanto, este projeto foi arquivado no final de dezembro de 2018. Isso permite evidenciar como há uma luta, em âmbito legal, em torno da definição de família o que corrobora essa instância como alvo de poder, na qual a lei tem exercido um papel determinante para o entendimento de família.

Além da legislação apresentada, merecem também destaque alguns marcos jurídicos que têm influenciado na produção do discurso da família, e de seus poderes e saberes, no âmbito da homoparentalidade.

Um primeiro movimento de reconhecimento da união entre pessoas do mesmo sexo como união estável deu-se em 2001, pela justiça gaúcha. Em 2011, esse reconhecimento foi feito pelo Supremo Tribunal Federal (STF), possibilitando a casais homossexuais de todo o Brasil constituírem união civil (Ação Direta de Inconstitucionalidade - ADI n. 4.277 e Arguição de Descumprimento de Preceito Fundamental - ADPF n. 132). E em 2015, o STF tornou possível a adoção por casais homossexuais.

Nesse contexto, em 2013, o Conselho Nacional de Justiça (CNJ) proibiu que os cartórios se negassem a realizar o casamento de casais homossexuais, tornando obrigatório a conversão da união estável em casamento (Resolução 175/2013). 
Portanto, tal configuração familiar é reconhecida atualmente por meio dessas decisões jurídicas, possibilitando-lhes cada vez mais acesso a direitos que por longos anos foram reconhecidos apenas a casais heterossexuais.

Ao ser possível a determinados sujeitos exercer direitos até então lhes negados, o sistema jurídico viabiliza, por meio de suas operações nas malhas do poder, que novas subjetividades possam ser produzidas. A possibilidade, por exemplo, da adoção por casais homossexuais, contribui para que esses sujeitos possam se produzir enquanto pais ou mães e seus filhos e filhas enquanto membros de uma família homoparental. Inseridos em relações de poder e saber, questionam, provocam e transformam as normas sociais.

Além disso, a possibilidade de não haver sempre um pai e uma mãe teve reflexos também na redação da certidão de nascimento. Encontramos hoje nesse documento as expressões 'filiação' e 'avós', em substituição a 'nome do pai' e 'nome da mãe', 'avós paternos' e 'avós maternos'. Desse modo, a redação desse documento abarca outras possibilidades de constituição familiar que fogem ao modelo nuclear.

O conjunto desses movimentos que produz essa nova forma de compreender e representar essa instância provocam a atualização do dispositivo da família. Em relação à atualização de um dispositivo, Gilles Deleuze (2005, p. 92) afirma que

A novidade de um dispositivo em relação aos que o precedem chamamos atualidade do dispositivo, a nossa atualidade. O novo é o atual. $\mathrm{O}$ atual não é o que somos, mas aquilo em que vamos nos tornando, aquilo que somos em devir, quer dizer, o Outro, o nosso devir-outro.

Essa atualização se dá na medida em que produz novas formas de vivenciar e controlar a família, através de novas relações de saber-poder-subjetividade que interpelam os sujeitos, resultantes da possibilidade de visibilização do pluralismo de configurações familiares. No entanto, é preciso considerar que esse processo de atualização do dispositivo corresponde a uma captura e ampliação do governo sobre os sujeitos, na medida em que os faz entrar em uma determinada ordem do discurso, baseada na heteronormatividade. Essa captura dos sujeitos, além disso, não deixa de produzir ao mesmo tempo outras exclusões.

Outro aspecto a considerar se trata da contra resistência que se produz com a ampliação do conceito de família, isto é, a emergência de grupos em defesa do retorno a um conceito unívoco dessa instância.

Ocorre que o reconhecimento da multiplicidade de configurações familiares incitou grupos religiosos e políticos que defendem o modelo de família nuclear como único aceitável. Assim, a desconstrução dos valores que apoiavam a família nuclear tradicional, provocou "o 
medo e a ira dos defensores de uma concepção de família naturalista e sagrada, fundada em valores religiosos e encarregada da missão - primeira e insubstituível - de assegurar a coesão social e a reprodução da espécie” (MELLO, 2005, p. 27). Tais grupos defensores “da família”, muitas vezes, atribuem determinadas mazelas da sociedade como resultante desse enfraquecimento da família em sua acepção nuclear.

Como produto da defesa desse modelo familiar, encontra-se o Projeto de Lei (PL) $\mathrm{n}^{\mathrm{o}}$ 6.583/2013 de autoria do deputado Anderson Ferreira, mais conhecido como Estatuto da Família. Este projeto foi aprovado em 2015 por Comissão Especial e pela Comissão de Constituição e Justiça da Câmara dos Deputados. Atualmente encontra-se em tramitação no Senado Federal. Este projeto, em seu Art. $2^{\circ}$ define por entidade familiar "o núcleo social formado a partir da união entre um homem e uma mulher, por meio de casamento ou união estável, ou ainda por comunidade formada por qualquer dos pais e seus descendentes" (PL $6.583 / 2013$, p. 2).

Assim, busca excluir, no âmbito da lei, o reconhecimento da diversidade familiar conquistado nos últimos anos. Não obstante, tem como justificativa o "enfrentamento das questões complexas a que estão submetidas as famílias num contexto contemporâneo", sendo um desses fatores a "desconstrução do conceito de família” (PL 6.583/2013, p. 6). Desse modo, esse projeto vem em combate ao pluralismo de arranjos familiares, ao mesmo tempo em que atribui a essa flexibilização do conceito a razão para as questões complexas da sociedade.

Vemos que a produção do discurso da família envolve, portanto, regimes de enunciação de diferentes ordens, produzindo alguns enunciados. Ao observarmos diferentes enunciados que compõem o discurso da família, podemos ver linhas de força que articulam saberes e poderes, apoiados em distintos regimes de verdades. Cada enunciado, assim, traz consigo, lutas de poder e produção de saber que tem por base uma vontade de verdade (FOUCAULT, 2014).

Diante disso, podemos apreender a potencialidade do dispositivo de governança da família na produção das subjetividades, de como o discurso jurídico que compõe essa instância atua sobre a produção dos sujeitos, de suas formas de ser e estar na cultura.

\section{Breves considerações}

Analisar a família como dispositivo na atualidade pode abrir um amplo leque de possibilidades, dentre as quais nos focamos em práticas relativas ao ordenamento jurídico. Tal sistema produz discursos que instituem verdades imersas em jogos de saber-poder e produção 
de subjetividades. Ao legitimar um determinado conceito de família que permite abarcar suas várias possibilidades, produz essas relações entre sujeitos enquanto famílias.

Problematizar essa instância como um dispositivo nos possibilita perceber alguns imbricamentos que a família exerce na produção social. Um dispositivo capilar que articula os sujeitos entre outros dispositivos. E este poder da família, esta centralidade da família na sociedade, é legitimada pelo sistema jurídico, que confere a essa instância toda uma normatização, um sistema de direitos, deveres e obrigações.

Evidenciamos a família como um dispositivo sobre o qual o sistema jurídico atua para regulamentar, legislar e controlar os sujeitos, tornando-a alvo do poder normalizador. A atuação desse sistema na produção da família torna-se, de um lado, um canal pelo qual se multiplicam as possibilidades de reconhecimento de arranjos familiares e, de outro, o instrumento de regulação, normalização, governo e controle dessas unidades. A família só é família enquanto tal, na forma da lei, o que possibilita a ela existir legalmente ou não e ter acesso ou não aos direitos instituídos pela legislação. Observar tais fatores nos mobilizou, portanto, a problematizar a produção do dispositivo da família na atualidade, o que nos permitiu dar visibilidade à sua atualização, a partir de leis e decisões jurídicas que legitimam a ampliação do conceito de família.

Entendemos que o reconhecimento das diferentes configurações familiares representa uma estratégia que possibilitou a atualização do dispositivo da família. Em relação a esse processo de atualização de um dispositivo, Garcia Fanlo (2011, p. 7) afirma que:

todo dispositivo tiene una genealogía y una historicidad que explica su régimen de aparición, reproducción, funcionamiento y crisis de la que resultará una nueva configuración de la red de saber/poder $\mathrm{y}$, consiguientemente, nuevas formas de experiencias.

Não realizamos aqui uma genealogia desse dispositivo, mas evidenciamos alguns aspectos históricos, partindo do olhar foucaultiano sobre a família moderna. Foucault (2001, 2006) nos possibilitou compreender, assim, seu regime de aparição, reprodução e funcionamento, que teve como centro a preocupação com o corpo e a sexualidade da criança, resultando desse processo a constituição da família celular-restrita-corporal-substancial (FOUCAULT, 2001).

Esse dispositivo, entretanto, entrou em crise por diversos fatores, não aprofundados aqui, mas dentre os quais podemos identificar as lutas para pôr em xeque a noção de família em sua acepção nuclear, exclusivamente ligada ao casamento (heterossexual) e à filiação biológica. Assim, vemos surgir novas noções de família e o reconhecimento legal das diversas 
configurações familiares, possibilitando a atualização deste dispositivo, e com isso outras formas de ser e existir, bem como outras relações de saber e poder.

Esses processos estão imbricados com a produção de discursos sobre a família, enredados aos diferentes campos de saber, sendo um deles o sistema jurídico. Reconhecemos neles, entretanto, lutas em defesa do conceito de família restrito ao modelo nuclear, representado hoje pelo Projeto de Lei 6.583/2013, mas que também encontra lugar em grupos que se intitulam contra a suposta 'ideologia de gênero' ${ }^{\text {. }}$

Observar essa produção discursiva do dispositivo da família corrobora as descontinuidades, as resistências, a instituição de verdades que tem por base lutas de saber e poder em torno daquilo que pode ser denominado "família". Lutas essas que são contínuas e que vão provocando novas condições de possibilidade para a emergência de novas conceituações sobre o termo e novas formas de (r)existência.

\section{REFERÊNCIAS}

BRASIL. Constituição da República Federativa do Brasil. Brasília, DF: Senado Federal: Centro Gráfico, 1988.

BRASIL. Lei ordinária n 10.836 de 9 de janeiro de 2004. Cria o Programa Bolsa Família e dá outras providências. Presidência da República, 2004. Disponível em: https://goo.gl/Th9i3Z. Acesso em: 15 nov. 2011.

BRASIL. Lei ordinária no 11.340 de 7 de agosto de 2006. Coíbe a violência doméstica e familiar contra a mulher. Presidência da República, 2006. Disponível em: https://goo.gl/CXm4AC. Acesso em: 10 maio 2017.

BRASIL. Projeto de Lei $\mathbf{n}^{\mathbf{0}}$ 612, de 29 de setembro de 2011 (do Senado Federal). Altera os arts. 1.723 e 1.726 do Código Civil, para permitir o reconhecimento legal da união estável entre pessoas do mesmo sexo. Disponível em: https://goo.gl/v1xhnA. Acesso em: 15 abr. 2017.

BRASIL. Projeto de Lei no 6.583, de 16 de outubro de 2013 (da Câmara dos Deputados). Dispõe sobre o Estatuto da Família e dá outras providências. Disponível em: https://goo.gl/mQ8fK9. Acesso em: 20 abr. 2017.

COSTA, A. B.; NARDI, H. C. O casamento "homoafetivo" e a política da sexualidade: implicações do afeto como justificativa das uniões de pessoas do mesmo sexo. Estudos Feministas, Florianópolis, n. 23, v. 1, p. 137-150, 2015. Disponível em: https://goo.gl/dY1Ssv. Acesso em: 14 mar. 2017.

${ }^{6}$ Ideologia de gênero, conforme Junqueira (2017), é uma expressão criada pela Igreja Católica para se opor aos Estudos de Gênero. Segundo o pesquisador, trata-se de uma "ofensiva [que] visa, além de recuperar espaço à Igreja em sociedades envolvidas em distintos processos de secularização, conter o avanço de políticas voltadas a garantir ou ampliar os direitos humanos de mulheres, pessoas não-heterossexuais e outros dissidentes da ordem sexual e de gênero. Para tanto, tais cruzados morais investem maciçamente na (re)naturalização das concepções de família, maternidade, parentesco, (hetero)sexualidade, diferença sexual.” (JUNQUEIRA, 2017, p. 26). 
DELEUZE, G. O mistério de Ariana. Lisboa: Veja, 2005.

DIAS, M. B. União homossexual: o preconceito e a justiça. Porto Alegre: Livraria do Advogado, 2000.

DIAS, M. B. Manual de Direito das Famílias. 14. ed. São Paulo: Revista dos Tribunais, 2015.

GARCIA FANLO, L. ¿Qué es un dispositivo?: Foucault, Deleuze, Agamben. A Parte Rei. Revista de Filosofia. n. 74, p. 1-8, mar., 2011. Disponível em: https://goo.gl/yDa5Nr. Acesso em: 05 maio 2016.

FOUCAULT, M. Os anormais: curso no Collegè de France (1974-1975). São Paulo: Martins Fontes, 2001.

FOUCAULT, M. A arqueologia do saber. Tradução de Luiz Felipe Baeta Neves. 7. ed. Rio de Janeiro: Forense Universitária, 2004.

FOUCAULT, M. O poder psiquiátrico: curso dado no Collège de France (1973-1974). São Paulo: Martins Fontes, 2006.

FOUCAULT, M. A ordem do discurso: aula inaugural do Collège de France, pronunciada em 2 de dezembro de 1970. São Paulo: Edições Loyola, 2014a.

FOUCAULT, M. Vigiar e punir: nascimento da prisão. 42. ed. Petrópolis, RJ: Vozes, 2014b.

FOUCAULT, M. História da sexualidade 1: a vontade de saber. São Paulo: Paz e Terra, 2015a.

FOUCAULT, M. Microfísica do poder. São Paulo: Paz e Terra, 2015b.

FISCHER, R. M. B. Foucault. In: OLIVEIRA, L. A. (Org.). Estudos do discurso: perspectivas teóricas. São Paulo: Parábola Editorial, p. 123-151, 2013.

JUNQUEIRA, R. D. "Ideologia de gênero": a gênese de uma categoria política reacionária - ou a promoção dos Direitos Humanos se tornou uma "ameaça à família natural"? In: RIBEIRO, P. R. de C. Debates contemporâneos sobre Educação para a Sexualidade. Editora da FURG, Rio Grande, p. 25-49, 2017.

MACHADO, R. Introdução: Por uma genealogia do poder. In: FOUCAULT, M. Microfísica do poder. São Paulo: Paz e Terra, 2015.

MELLO, L. Novas famílias: conjugalidade homossexual no Brasil contemporâneo. Rio de Janeiro: Garamont, 2005.

\section{Como referenciar este artigo}

KORNATZKI, Luciana; RIBEIRO, Paula Regina Costa. A produção da família no brasil contemporâneo: uma análise de leis e decisões jurídicas. Revista Ibero-Americana de Estudos em Educação, Araraquara, v. 14, n. esp. 2, p. 1304-1320, jul., 2019 E-ISSN: 19825587. DOI: 10.21723/riaee.v14iesp.2.12581

Submetido em: 30/09/2018

Revisões requeridas: 20/02/2019

Aprovado em: 30/04/2019

Publicado em: 25/06/2019 